\title{
Associations Between Cerebral Morphology and Objective Memory Performance in Patients With Subjective Cognitive Decline
}

\section{Qinjie Li}

Department of Gerontology, Shanghai Jiao Tong University Affiliated Sixth People's Hospital

\section{Anran Ren}

Department of Gerontology, Shanghai Jiao Tong university Affiliated Sixth People's Hospital

\section{Liang Cui}

Department of Gerontology, Shanghai Jiao Tong University Affiliated Sixth People's Hospital

\section{Xiaokang Sun}

Department of Gerontology, Shanghai Jiao Tong University Affiliated Sixth People's Hospital

\section{Yuan Zhong}

Department of Gerontology,Shanghai Jiao Tong University Affiliated Sixth People's Hospital

\section{Beiyun Wang}

Department of Gerontology, Shanghai Jiao Tong University Affiliated Sixth People's Hospital

\section{Ya Miao}

Department of Gerontology, Shanghai Jiao Tong university Affiliated Sixth people's hospital

Qihao Guo ( $\nabla$ qhguo@sjtu.edu.cn )

Shanghai Jiao Tong University

\section{Research}

Keywords: Subjective cognitive decline, Alzheimer's disease, gray matter atrophy, verbal learning test, visuospatial learning test, episodic memory

Posted Date: August 12th, 2020

DOI: https://doi.org/10.21203/rs.3.rs-55458/v1

License: (c) (i) This work is licensed under a Creative Commons Attribution 4.0 International License. Read Full License 


\section{Abstract}

Background: Previous studies reported subjective cognitive decline (SCD) linked to underlying the biomarker of early AD pathology. There is a lack of studies on whether structural brain changes and how cerebral morphology in association with verbal and visuospatial episodic memory performance.

Method: We combined VBM and SBM analysis for evaluating structural alterations in gray matter atrophy and cortical thickness among individuals with $S C D, M C l, A D$ and normal controls and investigated the associations between cerebral morphology and AVLT-H, BVMT-R performance in the whole samples and SCD, respectively.

Results: No significant regional gray matter volume atrophy and cortical thickness differences were found between SCD and normal controls. We found that immediate recall in verbal learning performance was significantly correlated with the loss of bilateral hippocampus volume in SCD group, furthermore, attention capacity (SDMT) was positively correlated with bilateral hippocampus atrophy and AVLT-IR in individuals with pre-MCI cognitive status.

Conclusions: Our results found hippocampal atrophy links much closer with verbal memory than visuospatial memory and immediate recall in verbal learning test was probably the primary deficit and maybe influenced by the attention capacity.

\section{Background}

Alzheimer's disease (AD) is the most common cause of dementia with a progressive preclinical course over several years to decades[1, 2]. Given its long prodromal period, AD treatment should begin as early as possible[3]. Although the focus is already moving forward to earlier clinical trials at the stage of mild cognitive impairment (MCl), $A D$ would be treated optimally in the "presymptomatic" or "preclinical" stages, before detectable cognitive impairment happens[4].

Subjective cognitive decline (SCD), the self-experienced persistent decline in cognitive among normal age-, gender-, and education- adjusted individuals, can indicate an at-risk stage of progressing to $\mathrm{MCl}$ or $\mathrm{AD}[5]$. Several studies have reported subjective cognitive complaints prospectively linked to underlying the biomarker of early $A D$ pathology[6, 7], such as amyloid- $\beta(A \beta)$, and likely progressed to further memory decline[8]. Approximately $2.3 \%$ and $6.6 \%$ of older people with subjective memory complaints will progress to dementia and $\mathrm{MCl}$ per year[9], and subjects with memory complaint are associated with a 6 fold increase in the risk of incident dementia compared to subjects with on memory complaint[10].

Structural brain research with morphology changes probably are good biological markers in SCD. Particular regions of the brain may be involved in the underlying pathology of AD. Study has shown an AD-like pattern of grey matter atrophy associated with SCD[11]. Previous studies have reported that individuals with SCD showed regional grey matter volume atrophy in temporal and frontal lobe[12], and cortical thickness reductions in bilateral entorhinal cortex and the parahippocampal cortex[13]. Moreover, one recent study has reported that SCD subjects with positive Aß42 would show lower regional gray matter volume (GMV) in left medial temporal than those with negative biomarker [14]. Taken together, structural brain morphology is expected to be a hopeful choice for aiding in diagnosing SCD.

Neuropsychological assessments are widely used in the clinical diagnosis of $\mathrm{MCl}$ and $\mathrm{AD}$, including neuropsychological tests battery and questionnaires. Recently, an increasing number of evidence focusing on the associations between neuropsychological symptoms and SCD. Due to the lack of objective cognitive impairment, more self-reported qustionnaires have been performed, such as Subjective Cognitive Decline Questionnaire (SCD-Q)[15], Memory Complaint Questionnaire (MAC-Q)[16], and Perception Questionnaire-Revised (IPQ-R) [17]. One recent study has found the SCDQuestionnaire 9 (SCD-Q9) was negatively correlated to the Auditory Verbal Learning Test-Long Delay Free Recall (AVLT- 
LDR) in 2689 elderly residents[18]. Auditory Verbal Learning Test-HuaShan (AVLT-H) was adapted from the California Verbal Learning Test, including 12 words over 5 trials were derived from Guo et al [19]. The AVLT-H provides a multitude of verbal learning and memory indices, including immediate recall (AVLT-IR, the total value of three times free recalls), free recall over short (AVLT-SDR) and long delays (AVLT-LDR), long cued recall (AVLT-LCR), recognition memory (AVLTREC). Short and long delay recall were separated by time intervals of other tests approximately 5 minutes and 20 minutes, respectively, in which the other nonverbal neuropsychological tests were administered. Brief Visuospatial Memory Test-Revised (BVMT-R) uses geometric designs and locations on a page as the items to be remembered [20], which follows relatively similar procedures as AVLT-H, including 3 times learning trials (BVMT-IR), free recalls after a 5 minute short time delay (BVMT-SDR) and a 20 minute long tome delay (BVMT-LDR), recognition (AVLT-REC) memory. Now, there is a lack of studies on whether and how the structural brain morphology is associated with verbal and visuospatial episodic memory performance.

Thus, in this study, we employed volume-based and surface-based analysis to detect reginal gray matter volume and cortical thickness morphology in individuals with controls, $S C D, M C l$ and $A D$, and investigate whether the characteristics of brain areas influenced the verbal and visuospatial memory performance. We hypothesized that the reginal brain volume atrophy and cortical thickness would be observed in SCD group compared with other groups. We also estimate that reginal volume atrophy and cortical thickness would be correlated with AVLT-H and BVMT-R performance in SCD.

\section{Methods}

\section{Participants}

A total of 198 participants were recruited from August 2018 to February 2020, including 51 normal controls (NC), 65 subjective cognitive decline (SCD), 44 mild cognitive impairment (MCI), 38 Alzheimer's disease (AD) from neuropsychological test room, Department of Geriatrics, Shanghai Sixth People's hospital, Shanghai, China. All participants were recruited in a standardized clinical and physical examination, provided their disease and medical history, had relevant laboratory screening, received a comprehensive battery of neuropsychological assessments and cranial MRI scanning. Inclusion criteria of all were aged more than 50 years old and less than 80 years old, educated more than 6 years, nearly normal eyesight and hearing, with on history of alcoholism, drug abuse, head trauma or other neuropsychiatric diseases, such as depression and anxiety, which would affect performance, without apparent abnormalities in folic acid, vitamin B12, rapid plasma regain, thyroid function, treponema pallidum particle agglutination. All participants signed informed consent. The study was approved by the ethics committee of Shanghai sixth people's hospital.

The inclusion criteria for SCD was based on the Jessen's [5]criteria: (a) subjective decline in memory, rather than other domains of cognition; (b) onset of SCD with the last 5 years; (c) concerns (worries) associated with SCD; (d) feeling of worse performance than others of the same age group; (e) normal performance on standardized cognitive tests with age-, gender-, and education-adjusted and did not reach the criteria for $\mathrm{MCl}$ or dementia. Individuals with no cognitive decline complaints or any worries about memory status and performed on standardized neuropsychological tests within normal range were include as controls.

Diagnosis of $\mathrm{MCl}$ was made if they had any one of the following criteria [21]: (1) they had impaired scores but did not reach the criteria for dementia, defined as $>1$ SD below the age-corrected normative mean, on two of the six neuropsychological measures in the same cognitive domain (i.e., memory, language, or attention/executive function); (2) they had impaired scores but did not reach the criteria for dementia, defined as S1SD below age-corrected normative mean, in each of the three cognitive domains. The criteria of $A D$ were based on the National Institute of Aging(NIA) and Alzheimer's Association (AA) criteria[22]. 


\section{Neuropsychological assessments}

All participants received extensive measures of memory, language, attention, executive function. The tests included Auditory Verbal Learning Test-HuaShan (AVLT-H)[23] and Brief Visuospatial Memory Test-Revised (BVMT-R) for episodic memory measure, Boston Naming Test (BNT) and Animal Verbal Fluency Test (AFT) for language measure, Shape Trails Test Parts A and B[24] for executive function measure, Symbol Digit Modalities Test (SDMT)[25] for attention capacity, processing speed measure. Cognitive screening tests of Mini-Mental State Examination(MMSE), Montreal Cognitive Assessment Basic Version (MoCA-B)[26] were also included. In addition, all subjects were administered the Subjective cognitive decline-interview (SCD-I)[27], Hamilton Depression Rating Scale (HAMD), Hamilton Anxiety Rating Scale (HAMA), Activities of daily living (ADL), Functional Activities Questionnaire (FAQ) to assess functional capacity in several different clinically relevant areas.

\section{Magnetic resonance imaging}

Brain MRI was performed with a 3.0-Tesla scanner (SIEMENS MAGNETOM Prisma 3.0T). T1-weighted 3-dimensional magnetization-prepared rapid gradient-echo volumetric images were used. $0.8 \times 0.8 \times 0.8 \mathrm{~mm}^{3}$ voxels acquired in the sagittal plane, the parameter as follows: matrix $=320 \times 320$, field of view $(F O V)=256 \times 256 \mathrm{~mm}^{2}$, slice thickness $=0.8 \mathrm{~mm}$, repetition time $(T R)=3000 \mathrm{~ms}$, echo time $(T E)=2.56 \mathrm{~ms}$, inversion time $=1100 \mathrm{~ms}$, flip angle $=7^{\circ}$, and number of slices $=$ 208.

VBM and SBM were conducted to determine differences in voxel volume and cortical thickness using the Computational Anatomy Toolbox (CAT12, http:// dbm.neuro.uni-jena.de/cat/) that is an extension toolbox of Statistical Parametric Mapping software (SPM12, http:// www.fil.ion.ucl.ac.uk/spm/software/spm12) on the MATLAB R2017a platform. Processing and analysis steps were carried out according to the default parameters in accordance with protocol in the manual of CAT12(http://www. neuro.uni-jena.de/cat12/CAT12-Manual.pdf).

\section{Voxel-based morphometry(VBM)}

The T1 images were spatially registered to the Montreal Neurological Institute (MNI) template and segmented into three voxel classes: white matter(WM), grey matter (GM) and cerebrospinal fluid (CSF). Then, segmented grey matter images were preserved to assess the amount of volume changes based on spatial registration, and the modulated normalized GM maps could reflect the regional tissue volumes differences. The total intracranial volume (TIV) was calculated and used as one covariate for all scans. We applied a 0.1 absolute masking threshold to the VBM data. The normalized grey matter images were smoothed using an $8 \mathrm{~mm}$ full width at half maximum(FWHM) Gaussian filter.

\section{Surface-based morphometry(SBM)}

SBM was used for the cortical thickness analysis, using CAT12 with default pipeline. There was performed in segment step using surface and thickness estimation analysis in the writing options. Estimation of central surface of hemispheres and cortical thickness were based on the projection-based method[28]. CT were extracted from central surface data based on the absolute mean curvature. Cortical thickness measures were resampled and smoothed using a 15 mm FWHM Gaussian kernel.

\section{Statistical analysis}

Demographic data analysis was performed with SPSS statistic 23 (IBM, New York, EUA). The Shapiro-Wilk test was used to investigate the distribution of data. ANOVA was applied on normally distributed variables to test groups differences, and Kruskal-Wallis $\mathrm{H}$ test was used if variables was not normal distribution. Pearson Chi-Square test was used to test the differences for gender comparison. Post Hoc comparisons using the Tukey HSD test or Games-Howell 
test were used to investigate the between-groups differences. Partial correlation analysis and Pearson correlation analysis were performed to calculate correlation between imaging and clinical scores, controlling for gender, age, education years and TIV.

We performed statistical analyses of MR data in the CAT12 applying ANOVA analysis for morphometric measures with TIV, age, gender as covariates for VBM (and for SBM, age and gender were used). we tested groups differences using a threshold of $p<0.05$ voxel-wise level with a family-wise error (FWE) correction for multiple comparisons. Post hoc tests of significant ANOVA findings were also performed to detect differences between every pair of groups. A small volume correction (SVC) tool available in SPM was used in the regions of interests (ROI), and only activated surviving regions in ANOVA analysis. When the FWE was too stringent, we set the statistical map at cluster level with $p<0.05$ corrected. We also report exploratory results at $\mathrm{p}<0.001$ uncorrected in between-group comparisons.

\section{Results}

\section{Demographics and behavioral results}

Demographic characteristics and behavioral results were summarized in Table 1 (at the end of the text). A total of 198 participants were included in analysis, including 51 cognitively normal controls(NC), 65 individuals with SCD, 44 individuals with $\mathrm{MCl}$ and 38 individuals with $\mathrm{AD}$. There were significant differences observed among 4 groups in terms of age $(P<0.05)$ and gender $(P<0.05)$. No significant difference was found in education years.

Compared with NC, AD showed significant decline in all cognitive performances. Compared with NC, MCl showed significant decline in all memory domain screening tests, except for BVMT-SDR performance. There was no significant difference in cognitive performances between NC and SCD. Compared with SCD, MCl showed obvious decline in MoCA$B$ and all sub-scores of AVLT performances. In addition, there were no significant difference in language and executive domains performance (AFT, BNT, STT-A, STT-B) among NC, SCD and MCl groups.

\section{Voxel-based morphometry-gray matter volume}

VBM analysis revealed group effects were summarized in Tables 2, and illustrated in Figure 1. Six main clusters of GM were detected, including bilateral hippocampus, bilateral parahippocampal and bilateral fusiform.

Post-hoc analysis of every pair of groups comparison were illustrated in Table 3. Compared with the group of NC, GM atrophy in $\mathrm{MCl}$ were reported in bilateral hippocampus ( $\mathrm{P}<0.05$, FWE corrected, SVC-based, cluster-wise level). Six clusters of GM atrophy in $A D$ were reported in bilateral fusiform, bilateral parahippocampal and bilateral hippocampus (all with $\mathrm{P}<0.05$, FWE corrected, SVC-based, voxel-wise level) comparing to the NC. The results in comparison between SCD and $A D$ were reported as the same pattern as the results in $N C$ and $A D$, six clusters of GM atrophy were reported. Compared with SCD, GM loss in left parahippocampal ( $P<0.05$, FWE corrected, SVC-based, cluster-wise level) was reported in $\mathrm{MCl}$. Compared with $\mathrm{MCl}, \mathrm{AD}$ showed significant $\mathrm{GM}$ loss in right hippocampus and parahippocampal $(\mathrm{P}<0.05$, FWE corrected, SVC-based, voxel-wise level).

\section{Surface-based morphometry-cortical thickness}

SBM analysis revealed group effects on the cortical thickness in right superior temporal, bilateral parahippocampal. The results were summarized in Table 4, and illustrated in Figure 2.

Post hoc analysis were carried out to detect the difference in every pair of groups, Table 5. Compared with NC, MCl participants showed a decreased cortical thickness in right superior temporal $(P<0.001$, uncorrected, voxel-wise level). Compared with NC, AD showed decreased cortical thickness in right superior temporal $(P<0.05, F W E$ corrected, cluster- 
wise level), right parahippocammpal ( $P<0.05$, FWE corrected, cluster-wise level). Three clusters of decreased cortical thickness were detected in AD group when comparing with SCD, localized to right hippocampus, right superior temporal and left parahippocampal all with a cluster-level threshold of FWE corrected $\mathrm{P}<0.05$. Compared with $\mathrm{MCl}$, a decreased cortical thickness in right superior temporal $(P<0.05$, FWE corrected, cluster-wise level) was reported in AD.

\section{Multiple regression analysis}

Multiple regression models were established between GM volumes and AVLT-H, BVMT-R, SDMT, controlling for age, gender, TIV as covariates, see in Table 6 and Figure 3. Significant positive correlations were found between AVLT-SDR with bilateral hippocampus and parahippocampal, respectively, with a voxel-wise level threshold of FWE corrected $\mathrm{P}<0.05$. Positive correlations were observed between AVLT-LDR and bilateral hippocampus, parahippocampal, respectively, all with a voxel-wise level threshold of FWE corrected $\mathrm{P}<0.05$. bilateral hippocampus, bilateral parahippocampal, bilateral fusiform were reported positively associated with AVLT-LCR at a voxel-wise level threshold of FWE corrected $\mathrm{P}<0.05$, respectively. AVLT-REC was observed showing positive correlations with bilateral hippocampus, bilateral parahippocampal and left fusiform with a voxel-wise level threshold of FWE corrected $\mathrm{P}<0.05$, respectively. And furthermore, AVLT-L, AVLT-IR and SDMT were all reported showing positive correlations with bilateral hippocampus, and all with voxel-wise level threshold of FWE corrected $P<0.05$. BVMT-IR, SDR, LDR were reported positively associated with bilateral hippocampus and bilateral parahippocampal, with a voxel-wise level threshold of FWE corrected $P<0.05$. And BVMT-REC was positively associated with bilateral hippocampus with a voxel-wise level threshold of FWE corrected $P<0.05$.

Moreover, there were significant positive correlations between cortical thickness and AVLT-H, BVMT-R, using multiple regression models and controlling for age, gender as covariates, in Table 6(at the end of the text) and Figure 4, 5. AVLTSDR and LDR were both observed showing positive correlations with right superior temporal and right parahippocampal with voxel-wise level threshold of FWE corrected $P<0.05$. There were positive correlations between AVLT-LCR and right superior temporal, bilateral parahippocampal, all with thresholds of voxel-wise level FWE corrected of $P<0.05$. In addition, AVLT-REC were reported positively associated with right superior temporal, bilateral parahippocampal at voxelwise level thresholds of FWE corrected $\mathrm{P}<0.05$. However, there were no significant relationships between CT and AVLT-IR, SDMT after FWE corrected of $\mathrm{P}<0.05$. BVMT-LDR and REC were reported showing positively associated with right superior temporal, bilateral parahippocampal. And furthermore, BVMT-IR was positively associated with right superior temporal and parahippocampal in voxel-wise level FWE corrected of $\mathrm{P}<0.05$.

\section{Correlation analysis}

In SCD group, partial correlation analysis was performed to detect the relationships between reginal grey matter volumes atrophy or cortical thickness and AVLT-H sub-scores, in Figure 5. AVLT-IR was observed showing significant positive correlations with left hippocampus $(r=0.284, p=0.026)$ and right hippocampus $(r=0.316, p=0.013)$, respectively. However, we did not find any of other AVHT sub-scores with significant correlations either in grey matter volumes or in cortical thickness areas. There was no significant correlation reported between any structural alternation and BVMT-R sub-sores. In NC and SCD groups, Pearson correlation analysis was performed between SDMT and gray matter volumes atrophy or cortical thickness. SDMT were reported positively correlated with left hippocampus $(r=0.250, p=0.007)$ and right hippocampus $(r=0.226 \mathrm{p}=0.015)$. We did not find SDMT with significant correlations in cortical thickness areas. Furthermore, we found SDMT was significantly positively correlated with AVLT-IR $(r=0.466 \mathrm{p}=0.000)$.

\section{Discussion}


In this study, we combined VBM and SBM analysis for evaluating structural alterations of gray matter atrophy and cortical thickness among individuals with $S C D, M C l, A D$ and normal controls, disclosing the association of structural alternations with verbal and visuospatial memory performance in the whole samples. Furthermore, we investigated the relationships of verbal and visuospatial memory performance with structural alternations in SCD or SDC and NC. We found that immediate recall in verbal learning performance was correlated with the loss of bilateral hippocampus volume in SCD group. To the best of our knowledge, this is the first study illustrated the correlated relationship between regional gray volume atrophy and immediate recall (AVLTIR) in individuals with SCD, furthermore, attention capacity (SDMT) was positively correlated with bilateral hippocampus atrophy and AVLT-IR in individuals with pre-MCl cognitive status, indicating that hippocampal atrophy links much closer with verbal memory than visuospatial memory and immediate recall in verbal learning test was probably the primary deficit and maybe influenced by the attention capacity.

Overall, the results obtained are in line with the previous studies[29-33], we observed the gray matter atrophy in bilateral hippocampus, bilateral parahippocampal, bilateral fusiform in AD groups compared with controls as well as SCD. Hippocampus and parahippocampal gyrus were widely known as the most two common structural MRI markers of progression to $\operatorname{AD}[34,35]$, the hippocampus showed progressive atrophy throughout the disease course. The results concord with previous study[36], bilateral hippocampus atrophy was found in SCD compared to AD. For the regional atrophy in fusiform, there was an evidence showed that fusiform was identified as the earliest change over the pathological stages [30], grey matter loss in fusiform has been shown to start in the medial temporal lobes and fusiform gyrus at least 3 years before subjects reach a diagnosis of $A D$, and then spread to the posterior temporal lobes and parietal lobes, and then eventually the frontal lobes[30,37], The severity of atrophy has been correlated with cognitive impairment severity. however, in our study we only found fusiform atrophy in subjects with AD. In addition, previous studies have identified that individuals with SCD showed structural gray matter volume reductions and cortical thinning in the bilateral entorhinal cortex, medial temporal, and frontotemporal regions compared to cognitively normal elders[14, 38], however, there was still previous study have found no gray matter differences in SCD compared to controls[39]. we did not find regional grey matter volume differences between SCD and NC in this study.

Consistent with the prior studies[13, 35, 40,41], differences in cortical thickness have been investigated and a pattern of regions associated with $\mathrm{MCl}$ and $\mathrm{AD}$ has been identified to include superior temporal, parahippocampal regions. Our findings indicated thinner cortical thickness in the right superior temporal and right parahippocampal in AD when comparing with controls. The severity of cortical reduction has been correlated with cognitive impairment severity, patients with $A D$ have the thinnest cortex in right superior temporal, patients with $\mathrm{MCl}$ and SCD exhibit intermediate measures, and normal controls show the greatest cortical thickness. Consistent with our findings, previous studies [42]demonstrated cortical thickness differences of the temporal lobes associated with disease progression and the reduction in superior temporal cortex was important for discriminating controls, stable $\mathrm{MCl}$ and $\mathrm{AD}$ [43]. Surrounding areas including the parahippocampal gyrus are considered sites of very early formation of neurofibrillary tangles in $A D$ including early volume loss. our results have some differences from previous reports[13, 44]: we did not find significant cortical thickness differences between controls and SCD, which may be related to a small sample size. In addition, other factors might have also contributed to discrepant findings between our study, e.g., the way of recruitment may influence the results within a specific sample.

Regression analyses showed that specific brain regions were significantly correlated with the values of both memory measures. Previous studies have found that left hemisphere structures are implicated in verbal memory processing[45], while right hemisphere structures support non-verbal/spatial memory[46]. Our results demonstrated both memory measures are more related to bihemispheric regions especially in gray matter atrophy areas. While spatial memory more support right hemisphere structures in cortical thickness areas. 
The wide temporal pole area was a highly strong predictor of immediate recall $[47,48]$, in this study we found that BVMT-IR showing much wider structural correlations than AVLT-IR, which not only contains the medial temporal area but also cortical thickness in right superior temporal. Immediate recall is a task that requires learning ability, including semantic and encoding processing $[47,48]$. In contrast to the immediate memory, the delayed recall task was restricted to the medial temporal lobe (MTL) area[48]. The delayed recall test reflects a long-term memory component[47], which was used to access ability of memory consolidation[49]. The essential role of medial temporal structures for the consolidation of new information has been known for a long time[50]. The results were consistent with a number of previous studies that have demonstrated relationships between the MTL sub-regions in hippocampus, parahippocampal and delayed recall[47, 51-53]. But except for that, we have found the cortical thickness in right superior temporal was correlated with short and long delay recalls. Our study found that the REC and LCR were correlated with wide areas, including bilateral hippocampus, bilateral parahippocampal, bilateral fusiform, right superior temporal. As with delayed recall, recognition memory was also reported to be most strongly associated with medial temporal structures, which is closely related to retrieval ability. Poor performance on delay recalls and recognition meant retention deficit, causing by the problem of memory consolidation[49]. Cued recall has been shown to provide an estimate of all items that the participant has stored, which has been reported to be highly associated with temporal regions [54]. Specifically, our results indicated that in addition to well-known hippocampus and parahippocampal, also inferior temporal (i.e. fusiform), superior temporal are also associated with REC and LCR.

Particularly, to determine the relationship between the structural alternations and verbal and visuospatial episodic memory in pre-MCl status, correlation analysis was conducted. AVLT-IR was observed showing significantly positive correlations with bilateral hippocampus. previous studies have found the SCD performed poorly on the episodic memory and correlated to left hippocampal volumes [18], and the amplitude of low-frequency fluctuations of resting-state functional MR imaging in the right middle occipital gyrus in SCD correlated to the AVLT immediate recall performance[39]. In our study, we did not find BVMT-R sub-scores significantly correlated with any structural alternation. Verbal episodic memory is strongly associated with medial temporal lobe function, in particular the hippocampus. Verbal episodic memory has been seen as the earliest cognitive domain to be affected in Alzheimer's disease[55]. Previous studies have found that left hippocampal volume was the strongest predictor of verbal memory, whereas right hippocampal volume was the strongest predictor of spatial memory[46], and spatial learning memory test was more strongly associated with hippocampal volumes than verbal learning memory tests[56]. It seems that non-verbal memory measures may have higher diagnostic value, however, those studies were based on the individuals with $\mathrm{MCl}$ or $\mathrm{AD}$. One recent study has demonstrated that in cognitive normal individuals only when amyloidosis and hippocampal atrophy are both present, significant associations with decline in visuospatial episodic memory could be detected, but when individuals without detectable amyloid levels, hippocampal atrophy predicted the rate of decline in tests of verbal memory only[57]. Combined with our results, hippocampal atrophy links much closer with verbal memory than visuospatial memory, to some extent. SDMT is a digit test that requires attention, perceptual speed, visual scanning speed, and tracking and is very sensitive to various neurological disorders. In our results, SDMT was positively correlated with bilateral hippocampus atrophy and AVLT-IR, respectively, in individuals with pre-MCl cognitive status, indicating that immediate recall of verbal learning was probably the primary deficit and maybe influenced by the attention capacity.

\section{Conclusion}

In this study, we found the structural alterations among individuals with $\mathrm{SCD}, \mathrm{MCl}, \mathrm{AD}$ and normal controls using VBM and SBM and investigated the associations between cerebral morphology and AVLT-H, BVMT-R performance in the whole samples and SCD, respectively. We found hippocampal atrophy significantly associated with AVLT-IR, and SDMT was positively correlated with bilateral hippocampus atrophy and AVLT-IR. In our results, verbal episodic memory was 
probably the primary deficit in SCD, especially immediate recall performance, which possibly influenced by the attention capacity.

\section{Limitation}

Our study had several limitations. Firstly, the results may be related to a small sample size. Considering that this is an ongoing research project, further analyses with more participants should be conducted. Secondly, we did not take information of biomarkers (such as $A \beta$, tau) into consideration. Future studies that combine PET or multimodal MR techniques be conducted. Thirdly, we only collected data on episodic memory performance in this study. It would be meaningful to perform more functional tests (i.e., executive function) in the future to estimate the brain-behavioral relationship.

\section{Abbreviations}

SCD

subjective cognitive decline; AD:Alzheimer's disease; VBM:voxel-based morphometry; SBM:surfaced-based morphometry; MCl:mild cognitive impairment; AVLT-H:Auditory Verbal Learning Test-HuaShan; BVMT-R:Brief Visuospatial Memory Test-Revised; SDMT:Symbol Digit Modalities Test; AVLT-IR:Auditory Verbal Learning Testimmediate recall; $A \beta$ :amyloid- $\beta$; GMV:gray matter volume; AVLT-LDR:Auditory Verbal Learning Test-long delay recall; AVLT-SDR:Auditory Verbal Learning Test-short delay recall; AVLT-LCR:Auditory Verbal Learning Test-long cued recall; AVLT-REC:Auditory Verbal Learning Test-recognition; BVMT-IR:Brief Visuospatial Memory Test-immediate recall; BVMTSDR:Brief Visuospatial Memory Test- short delay recall; BVMT-LDR:Brief Visuospatial Memory Test- long delay recall; BVMT-REC:Brief Visuospatial Memory Test-recognition; NC:normal controls; BNT:Boston Naming Test; AFT:Animal Verbal Fluency Test; MMSE:Mini-Mental State Examination; MoCA-B:Montreal Cognitive Assessment Basic Version; STTA:Shape Trails Test Part A; STT-B:Shape Trails Test Parts B TIV:total intracranial volume; SCV:small volume correction; FWE:family-wise error; GM:gray matter; CT:cortical thickness

\section{Declarations}

\section{Acknowledgements}

This research did not receive any specific grant from funding agencies in the public, commercial or not-for-profit sectors.

\section{Author's contributions}

Qinjie Li, Qihao Guo contributed to the study concept and design. Qinjie Li, Qihao Guo contributed to the acquisition, analysis, or interpretation of the data, as well as critical revision of the manuscript for important intellectual content. Qinjie Li performed the statistical analysis. Qihao Guo obtained the funding. Anran Ren, Liang Cui, Xiaokang Sun, Yuan Zhong, Beiyun Wang, Ya Miao provided administrative, technical, or material support. All authors read and approved the final manuscript.

\section{Funding}

This study was funded by the National Key R\&D Program of China (2016YFC1306305, 2018YFE0203600) and Shanghai Municipal Science and Technology Major Project (No. 2018SHZDZX01) and ZJLab.

\section{Availability of data and materials}


The datasets used and/or analyzed during the current study are not publicly available due to ongoing analysis and manuscript preparation but are available from the corresponding author on reasonable request.

\section{Ethics approval and consent to participate}

All participants signed informed consent. The study was approved by the ethics committee of Shanghai sixth people's hospital.

\section{Consent for publication}

Not applicable

\section{Competing interests}

The authors declare no conflict of interest, financial or otherwise.

\section{Author details}

1, 2, *: Department of Gerontology, Shanghai Jiao Tong University Affiliated Sixth People's Hospital, Shanghai, China

\section{References}

1. Jack CR, Knopman DS, Jagust WJ, Petersen RC, Weiner MW, Aisen PS, et al. Tracking pathophysiological processes in Alzheimer's disease: an updated hypothetical model of dynamic biomarkers. The Lancet Neurology. 2013;12(2):207-16.

2. Villemagne VL, Burnham S, Bourgeat P, Brown B, Ellis KA, Salvado O, et al. Amyloid $\beta$ deposition, neurodegeneration, and cognitive decline in sporadic Alzheimer's disease: a prospective cohort study. The Lancet Neurology. 2013;12(4):357-67.

3. Sperling R, Mormino E, Johnson K. The evolution of preclinical Alzheimer's disease: implications for prevention trials. Neuron. 2014;84(3):608-22.

4. Sperling RA, Aisen PS, Beckett LA, Bennett DA, Craft S, Fagan AM, et al. Toward defining the preclinical stages of Alzheimer's disease: recommendations from the National Institute on Aging-Alzheimer's Association workgroups on diagnostic guidelines for Alzheimer's disease. Alzheimers Dement. 2011;7(3):280-92.

5. Jessen F, Amariglio RE, van Boxtel M, Breteler M, Ceccaldi M, Chetelat G, et al. A conceptual framework for research on subjective cognitive decline in preclinical Alzheimer's disease. Alzheimers Dement. 2014;10(6):844-52.

6. Amariglio RE, Becker JA, Carmasin J, Wadsworth LP, Lorius N, Sullivan C, et al. Subjective cognitive complaints and amyloid burden in cognitively normal older individuals. Neuropsychologia. 2012;50(12):2880-6.

7. Amariglio RE, Buckley RF, Mormino EC, Marshall GA, Johnson KA, Rentz DM, et al. Amyloid-associated increases in longitudinal report of subjective cognitive complaints. Alzheimers Dement (N Y). 2018;4:444-9.

8. Gallassi R, Oppi F, Poda R, Scortichini S, Stanzani Maserati M, Marano G, et al. Are subjective cognitive complaints a risk factor for dementia? Neurol Sci. 2010;31(3):327-36.

9. Mitchell AJ, Beaumont H, Ferguson D, Yadegarfar M, Stubbs B. Risk of dementia and mild cognitive impairment in older people with subjective memory complaints: meta-analysis. Acta Psychiatr Scand. 2014;130(6):439-51.

10. Abner EL, Kryscio RJ, Caban-Holt AM, Schmitt FA. Baseline subjective memory complaints associate with increased risk of incident dementia: the PREADVISE trial. J Prev Alzheimers Dis. 2015;2(1):11-6.

11. Peter J, Scheef L, Abdulkadir A, Boecker H, Heneka M, Wagner M, et al. Gray matter atrophy pattern in elderly with subjective memory impairment. Alzheimers Dement. 2014;10(1):99-108. 
12. Dore V, Villemagne VL, Bourgeat P, Fripp J, Acosta O, Chetelat G, et al. Cross-sectional and longitudinal analysis of the relationship between Abeta deposition, cortical thickness, and memory in cognitively unimpaired individuals and in Alzheimer disease. JAMA Neurol. 2013;70(7):903-11.

13. Meiberth D, Scheef L, Wolfsgruber S, Boecker H, Block W, Traber F, et al. Cortical thinning in individuals with subjective memory impairment. J Alzheimers Dis. 2015;45(1):139-46.

14. Hu X, Teunissen CE, Spottke A, Heneka MT, Duzel E, Peters O, et al. Smaller medial temporal lobe volumes in individuals with subjective cognitive decline and biomarker evidence of Alzheimer's disease-Data from three memory clinic studies. Alzheimers Dement. 2019;15(2):185-93.

15. Gifford KA, Liu D, Romano R, 3rd, Jones RN, Jefferson AL. Development of a subjective cognitive decline questionnaire using item response theory: a pilot study. Alzheimers Dement (Amst). 2015;1(4):429-39.

16. Vogel A, Salem LC, Andersen BB, Waldemar G. Differences in quantitative methods for measuring subjective cognitive decline - results from a prospective memory clinic study. Int Psychogeriatr. 2016;28(9):1513-20.

17. Hurt CS, Burns A, Brown RG, Barrowclough C. Perceptions of subjective memory complaint in older adults: the Illness Perception Questionnaire-Memory (IPQ-M). Int Psychogeriatr. 2010;22(5):750-60.

18. Hao L, Wang X, Zhang L, Xing Y, Guo Q, Hu X, et al. Prevalence, Risk Factors, and Complaints Screening Tool Exploration of Subjective Cognitive Decline in a Large Cohort of the Chinese Population. J Alzheimers Dis. 2017;60(2):371-88.

19. GUO Qi-hao,SUN Yi-min,YU Pei-min,HONG Zhen,LV Chuan-zhen. Norm of auditory verbal learning test in the normal aged in china community. Chinese Journal of Clinical Psychology. 2007, 15(2):132-141.

20. Duff K. Demographically corrected normative data for the Hopkins Verbal Learning Test-Revised and Brief Visuospatial Memory Test-Revised in an elderly sample. Appl Neuropsychol Adult. 2016;23(3):179-85.

21. Bondi MW, Edmonds EC, Jak AJ, Clark LR, Delano-Wood L, McDonald CR, et al. Neuropsychological criteria for mild cognitive impairment improves diagnostic precision, biomarker associations, and progression rates. J Alzheimers Dis. 2014;42(1):275-89.

22. Jack CR, Jr., Albert MS, Knopman DS, McKhann GM, Sperling RA, Carrillo MC, et al. Introduction to the recommendations from the National Institute on Aging-Alzheimer's Association workgroups on diagnostic guidelines for Alzheimer's disease. Alzheimers Dement. 2011;7(3):257-62.

23. Qianhua Zhao, Qihao Guo, Xiaoniu Liang, Meirong Chen, Yan Zhou, Ding Ding, et al. Auditory Verbal Learning Test is Superior to Rey-Osterrieth Complex Figure Memory for Predicting Mild Cognitive Impairment to Alzheimer's Disease. Curr Alzheimer Res. 2015;12(6):520-6.

24. Zhao Q, Guo Q, Li F, Zhou Y, Wang B, Hong Z. The Shape Trail Test: application of a new variant of the Trail making test. PLoS One. 2013;8(2):e57333.

25. Fellows RP, Schmitter-Edgecombe M. Symbol Digit Modalities Test: Regression-Based Normative Data and Clinical Utility. Arch Clin Neuropsychol. 2019;35(1):105-15.

26. Chen KL, Xu Y, Chu AQ, Ding D, Liang XN, Nasreddine ZS, et al. Validation of the Chinese Version of Montreal Cognitive Assessment Basic for Screening Mild Cognitive Impairment. J Am Geriatr Soc. 2016;64(12):e285-e90.

27. Miebach L, Wolfsgruber S, Polcher A, Peters O, Menne F, Luther K, et al. Which features of subjective cognitive decline are related to amyloid pathology? Findings from the DELCODE study. Alzheimers Res Ther. 2019;11(1):66.

28. Dahnke R, Yotter RA, Gaser C. Cortical thickness and central surface estimation. Neuroimage. 2013;65:336-48.

29. Hanggi J, Streffer J, Jancke L, Hock C. Volumes of lateral temporal and parietal structures distinguish between healthy aging, mild cognitive impairment, and Alzheimer's disease. J Alzheimers Dis. 2011;26(4):719-34.

30. Jennifer L Whitwell, Scott A Przybelski, Stephen D Weigand, David S Knopman, Bradley F Boeve, Ronald C Petersen, et,al. 3D Maps from Multiple MRI Illustrate Changing Atrophy Patterns as Subjects Progress from MCI to AD. Brain.

Page $11 / 24$ 
2007;130(Pt 7):1777-86.

31. A T Du, N Schuff, D Amend, M P Laakso, Y Y Hsu, W J Jagust, et,al. Magnetic resonance imaging of the entorhinal cortex and hippocampus in mild cognitive impairment and Alzheimer's disease. J Neurol Neurosurg Psychiatry. 2001;71(4):441-7.

32. Wolf H, Hensel A, Kruggel F, Riedel-Heller SG, Arendt T, Wahlund LO, et al. Structural correlates of mild cognitive impairment. Neurobiol Aging. 2004;25(7):913-24.

33. Lin Y, Shan PY, Jiang WJ, Sheng C, Ma L. Subjective cognitive decline: preclinical manifestation of Alzheimer's disease. Neurol Sci. 2019;40(1):41-9.

34. Jack CR, Jr., Petersen RC, Xu YC, O'Brien PC, Smith GE, Ivnik RJ, et al. Prediction of AD with MRI-based hippocampal volume in mild cognitive impairment. Neurology. 1999;52(7):1397-403.

35. Shannon L Risacher, Andrew J Saykin, John D West, Li Shen, Hiram A Firpi, Brenna C McDonald, et al. Baseline MRI Predictors of Conversion from MCI to Probable AD in the ADNI Cohort. urr Alzheimer Res. 2009;6(4):347-61.

36. Perrotin A, de Flores R, Lamberton F, Poisnel G, La Joie R, de la Sayette V, et al. Hippocampal Subfield Volumetry and 3D Surface Mapping in Subjective Cognitive Decline. J Alzheimers Dis. 2015;48 Suppl 1:S141-50.

37. Whitwell JL. Progression of atrophy in Alzheimer's disease and related disorders. Neurotox Res. 2010;18(3-4):33946.

38. Liang L, Zhao L, Wei Y, Mai W, Duan G, Su J, et al. Structural and Functional Hippocampal Changes in Subjective Cognitive Decline From the Community. Front Aging Neurosci. 2020;12:64.

39. Yu Sun, Zhengjia Dai, Yuxia Li, Can Sheng, Hongyan Li, Xiaoni Wang, et, al. Subjective cognitive decline: mapping functional and structural brain changes-a combined resting-state functional and structural MR imaging study. Radiology. 2016;281(1):185-92.

40. Oliveira PP, Jr., Nitrini R, Busatto G, Buchpiguel C, Sato JR, Amaro E, Jr. Use of SVM methods with surface-based cortical and volumetric subcortical measurements to detect Alzheimer's disease. J Alzheimers Dis.

2010;19(4):1263-72.

41. S E Arnold, B T Hyman, J Flory, A R Damasio, G W Van Hoesen.The Topographical and Neuroanatomical Distribution of Neurofibrillary Tangles and Neuritic Plaques in the Cerebral Cortex of Patients with Alzheimer's Disease. Cereb Cortex.1991;1(1):103-16.

42. Pacheco J, Goh JO, Kraut MA, Ferrucci L, Resnick SM. Greater cortical thinning in normal older adults predicts later cognitive impairment. Neurobiol Aging. 2015;36(2):903-8.

43. DeVivo R, Zajac L, Mian A, Cervantes-Arslanian A, Steinberg E, Alosco ML, et al. Differentiating Between Healthy Control Participants and Those with Mild Cognitive Impairment Using Volumetric MRI Data. J Int Neuropsychol Soc. 2019;25(8):800-10.

44. Sun Y, Wang X, Wang Y, Dong H, Lu J, Scheininger T, et al. Anxiety correlates with cortical surface area in subjective cognitive decline: APOE epsilon4 carriers versus APOE epsilon4 non-carriers. Alzheimers Res Ther. 2019;11(1):50.

45. W M Kelley , F M Miezin, K B McDermott, R L Buckner, M E Raichle, N J Cohen, et,al. Hemispheric Specialization in Human Dorsal Frontal Cortex and Medial Temporal Lobe for Verbal and Nonverbal Memory Encoding. Neuron. 1998; 20(5):927-36.

46. L de Toledo-Morrell, B Dickerson, M P Sullivan, C Spanovic, R Wilson, D A Bennett. Hemispheric Differences in Hippocampal Volume Predict Verbal and Spatial Memory Performance in Patients With Alzheimer's Disease. Hippocampus.2000;10(2):136-42.

47. Ahn HJ, Seo SW, Chin J, Suh MK, Lee BH, Kim ST, et al. The cortical neuroanatomy of neuropsychological deficits in mild cognitive impairment and Alzheimer's disease: a surface-based morphometric analysis. Neuropsychologia. 2011;49(14):3931-45.

Page $12 / 24$ 
48. Wolk DA, Dickerson BC, Alzheimer's Disease Neuroimaging I. Fractionating verbal episodic memory in Alzheimer's disease. Neuroimage. 2011;54(2):1530-9.

49. Kang SH, Park YH, Lee D, Kim JP, Chin J, Ahn Y, et al. The Cortical Neuroanatomy Related to Specific Neuropsychological Deficits in Alzheimer's Continuum. Dement Neurocogn Disord. 2019;18(3):77-95.

50. Squire LR, Wixted JT. The cognitive neuroscience of human memory since H.M. Annu Rev Neurosci. 2011;34:25988.

51. R J Killiany, B T Hyman, T Gomez-Isla, M B Moss, R Kikinis, F Jolesz, et,al. MRI measures of entorhinal cortex vs hippocampus in preclinical AD. Neurology. 2002;58(8):1188-96.

52. Zhao Q, Lv Y, Zhou Y, Hong Z, Guo Q. Short-term delayed recall of auditory verbal learning test is equivalent to longterm delayed recall for identifying amnestic mild cognitive impairment. PLoS One. 2012;7(12):e51157.

53. Saloner R, Casaletto KB, Marx G, Dutt S, Vanden Bussche AB, You M, et al. Performance on a 1-week delayed recall task is associated with medial temporal lobe structures in neurologically normal older adults. Clin Neuropsychol. 2018;32(3):456-67.

54. Epelbaum S, Bouteloup V, Mangin JF, La Corte V, Migliaccio R, Bertin H, et al. Neural correlates of episodic memory in the Memento cohort. Alzheimers Dement (N Y). 2018;4:224-33.

55. Backman L, Jones S, Berger AK, Laukka EJ, Small BJ. Cognitive impairment in preclinical Alzheimer's disease: a meta-analysis. Neuropsychology. 2005;19(4):520-31.

56. Bonner-Jackson A, Mahmoud S, Miller J, Banks SJ. Verbal and non-verbal memory and hippocampal volumes in a memory clinic population. Alzheimers Res Ther. 2015;7(1):61.

57. Bilgel M, An Y, Helphrey J, Elkins W, Gomez G, Wong DF, et al. Effects of amyloid pathology and neurodegeneration on cognitive change in cognitively normal adults. Brain. 2018;141(8):2475-85.

\section{Tables}


Table 1

subject demographics and neuropsychological assessments

\begin{tabular}{|c|c|c|c|c|c|}
\hline & $N C(n=51)$ & $\operatorname{SCD}(n=65)$ & $\operatorname{MCl}(n=44)$ & $A D(n=38)$ & P val \\
\hline Age & $65.20 \pm 7.34$ & $65.17 \pm 6.91$ & $65.93 \pm 7.58$ & $69.05 \pm 7.34^{\mathrm{e}}$ & $0.047^{\star}$ \\
\hline Education & $12.31 \pm 3.18$ & $12.35 \pm 3.06$ & $12.36 \pm 2.72$ & $11.30 \pm 3.31$ & $0.171^{\#}$ \\
\hline Female (\%) & 78.43 & $69.23^{a}$ & $50.00^{d}$ & $60.53^{c, f}$ & $0.026 \S$ \\
\hline MMSE & $28.37 \pm 1.48$ & $28.05 \pm 1.54$ & $27.23 \pm 1.76^{b}$ & $21.58 \pm 1.91^{\mathrm{c}, \mathrm{e}, \mathrm{f}}$ & $0.000^{\#}$ \\
\hline MoCA-B & $26.53 \pm 1.83$ & $25.54 \pm 2.76$ & $23.11 \pm 3.23^{b, d}$ & $16.53 \pm 3.60^{c, e, f}$ & $0.000^{\star}$ \\
\hline AVLT-SDR & $6.75 \pm 1.74$ & $6.37 \pm 2.21$ & $2.55 \pm 1.50^{b, d}$ & $0.87 \pm 1.30^{c, e, f}$ & $0.000^{\#}$ \\
\hline AVLT-LDR & $6.57 \pm 1.96$ & $5.95 \pm 2.25$ & $1.91 \pm 1.41^{b, d}$ & $0.29 \pm 0.65^{c, e, f}$ & $0.000^{\#}$ \\
\hline AVLT-LCR & $6.49 \pm 2.46$ & $5.85 \pm 2.29$ & $2.23 \pm 1.6^{b, d}$ & $0.79 \pm 1.26^{c, e, f}$ & $0.000^{\#}$ \\
\hline AVLT-REC & $22.02 \pm 1.52$ & $21.74 \pm 2.20$ & $17.27 \pm 2.21^{\mathrm{b}, \mathrm{d}}$ & $16.34 \pm 3.22^{\mathrm{c}, \mathrm{e}}$ & $0.000^{\#}$ \\
\hline AVLT-IR & $19.80 \pm 3.80$ & $17.88 \pm 4.73$ & $12.50 \pm 2.31^{b, d}$ & $10.08 \pm 3.01^{c, e, f}$ & $0.000^{\#}$ \\
\hline STT-A & $45.51 \pm 10.34$ & $47.86 \pm 14.64$ & $52.50 \pm 19.05$ & $77.39 \pm 28.83^{c, e, f}$ & $0.000^{\#}$ \\
\hline STT-B & $118.08 \pm 35.43$ & $117.74 \pm 26.00$ & $135.89 \pm 41.03$ & $183.50 \pm 63.50^{\mathrm{c}, \mathrm{e}, \mathrm{f}}$ & $0.000^{\#}$ \\
\hline AFT & $18.04 \pm 3.54$ & $16.71 \pm 2.93$ & $16.23 \pm 3.59$ & $13.26 \pm 3.53^{c, e, f}$ & $0.000^{\#}$ \\
\hline BNT(30 items) & $24.24 \pm 2.80$ & $24.49 \pm 2.88$ & $23.14 \pm 4.08$ & $19.61 \pm 3.85^{c, e, f}$ & $0.000^{\#}$ \\
\hline SDMT & $42.39 \pm 9.36$ & $38.09 \pm 10.89$ & $33.77 \pm 11.38^{b}$ & $21.29 \pm 9.62^{c, e, f}$ & $0.000^{\star}$ \\
\hline BVMT-IR & $21.29 \pm 0.96$ & $19.82 \pm 0.89$ & $15.82 \pm 0.99^{b}$ & $6.03 \pm 0.87^{c, e, f}$ & $0.000^{\#}$ \\
\hline BVMT-SDR & $9.10 \pm 0.38$ & $8.89 \pm 0.36$ & $7.23 \pm 0.51$ & $2.18 \pm 0.43^{c, e, f}$ & $0.000^{\#}$ \\
\hline BVMT-LDR & $9.14 \pm 0.38$ & $8.92 \pm 0.35$ & $7.07 \pm 0.54^{b}$ & $2.05 \pm 0.37^{c, e, f}$ & $0.000^{\#}$ \\
\hline BVMT-REC & $11.88 \pm 0.06$ & $11.54 \pm 0.16$ & $11.00 \pm 0.22^{b}$ & $8.16 \pm 0.39^{c, e, f}$ & $0.000^{\#}$ \\
\hline \multicolumn{6}{|c|}{ 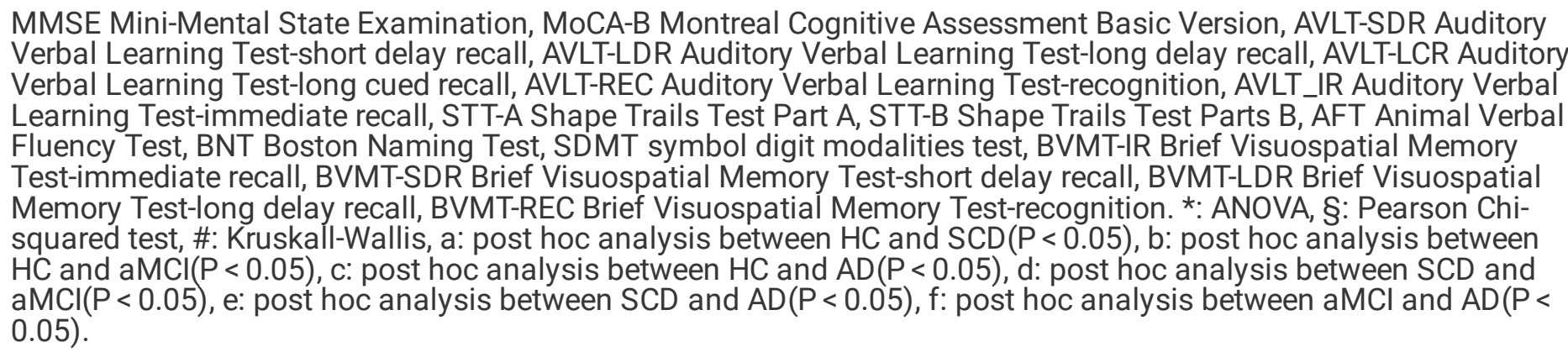 } \\
\hline
\end{tabular}


Table 2

Results of VBM analysis of group effects

\begin{tabular}{|lllllll|}
\hline Areas & K voxel & $\mathbf{P}_{\text {(FWE-Corr) }}{ }^{*}$ & & Peak F value & \multicolumn{3}{c|}{ MNI coordinates } \\
\cline { 5 - 8 } & & & & $\mathbf{X}$ & $\mathbf{y}$ & $\mathbf{z}$ \\
\hline Left hippocampus & 1530 & 0.000 & 38.81 & -27 & -14 & -12 \\
\hline Left parahippocampal & 1260 & 0.000 & 32.08 & -26 & -29 & -8 \\
\hline Left fusiform & 473 & 0.000 & 13.91 & -23 & -8 & -38 \\
\hline Right parahippocampal & 1861 & 0.000 & 33.25 & 27 & -26 & -8 \\
\hline Right hippocampus & 1507 & 0.000 & 29.89 & 27 & -12 & -12 \\
\hline Right fusiform & 451 & 0.000 & 21.68 & 24 & -17 & -27 \\
\hline * $P<0.05$, voxel-wise level, FWE correction & & & & \\
\hline
\end{tabular}

Table 3

Significant results of grey matter volume in every pair of groups

\begin{tabular}{|c|c|c|c|c|c|c|}
\hline & \multirow[t]{2}{*}{ Areas } & \multirow[t]{2}{*}{ K voxel } & \multirow[t]{2}{*}{$\mathbf{P}$} & \multicolumn{3}{|c|}{ MNI coordinates } \\
\hline & & & & $\mathbf{x}$ & $\mathbf{y}$ & $\mathbf{z}$ \\
\hline \multirow[t]{2}{*}{$\mathrm{NC}>\mathrm{MCl}$} & Left hippocampus & 286 & $0.006^{*}$ & -27 & -12 & -12 \\
\hline & Right hippocampus & 23 & $0.043^{*}$ & 21 & -15 & -14 \\
\hline \multirow[t]{6}{*}{$N C>A D$} & Left fusiform & 157 & $0.000 * \star$ & -36 & -20 & -29 \\
\hline & Left hippocampus & 751 & $0.000 * *$ & -27 & -12 & -14 \\
\hline & Left parahippocampal & 898 & $0.000 * \star$ & -27 & -23 & -21 \\
\hline & right parahippocampal & 965 & $0.000 * \star$ & 30 & -30 & -12 \\
\hline & Right hippocampus & 1054 & $0.000 * *$ & 26 & -30 & -8 \\
\hline & Right fusiform & 191 & $0.000 * \star$ & 36 & -24 & -18 \\
\hline $\mathrm{SCD}>\mathrm{MCl}$ & Left parahippocampal & 369 & $0.004^{\star}$ & -26 & -15 & -12 \\
\hline \multirow[t]{6}{*}{$S C D>A D$} & Left fusiform & 185 & $0.000 * \star$ & -33 & -20 & -21 \\
\hline & Left hippocampus & 779 & $0.000 * \star$ & -27 & -14 & -14 \\
\hline & Left parahippocampal & 1168 & $0.000 * \star$ & -27 & -23 & -21 \\
\hline & Right hippocampus & 1116 & $0.000 * \star$ & 27 & -27 & -9 \\
\hline & Right fusiform & 447 & $0.000 * \star$ & 23 & 6 & -42 \\
\hline & Right parahippocampal & 1380 & $0.000 * \star$ & 30 & -23 & -18 \\
\hline \multirow[t]{2}{*}{$\mathrm{MCl}>\mathrm{AD}$} & Right hippocampus & 259 & $0.000 * \star$ & 27 & -27 & -9 \\
\hline & Right parahippocampal & 42 & $0.000 * \star$ & 30 & -30 & -12 \\
\hline \multicolumn{7}{|c|}{ *P $<0.05$, FWE corrected, small volume correction, cluster-wise level } \\
\hline
\end{tabular}


Table 4

Results of SBM analysis of group effects

\begin{tabular}{|llllllll|}
\hline Area & K voxel & $\mathbf{P}_{(\text {FWE-Corr) }}{ }^{*}$ & Peak F value & \multicolumn{3}{c|}{ MNI coordinates } \\
\cline { 5 - 9 } & & & & & $\mathbf{x}$ & $\mathbf{y}$ & $\mathbf{z}$ \\
\hline Right superior temporal & 77 & 0.001 & 12.08 & 54 & -17 & -7 \\
\hline Right ParaHippocampal & 155 & 0.000 & 11.60 & 29 & -9 & -34 \\
\hline Left ParaHippocampal & 138 & 0.000 & 11.05 & -24 & 1 & -27 \\
\hline *P<0.05, voxel-wise level, FWE correction & & & & \\
\hline
\end{tabular}

Table 5

Significant results of cortical thickness in every pair of groups

\begin{tabular}{|c|c|c|c|c|c|c|}
\hline & \multirow[t]{2}{*}{ Areas } & \multirow[t]{2}{*}{ K voxel } & \multirow[t]{2}{*}{ P value } & \multicolumn{3}{|c|}{ MNI coordinates } \\
\hline & & & & $\mathbf{x}$ & $\mathbf{y}$ & $\mathbf{z}$ \\
\hline $\mathrm{NC}>\mathrm{MCl}$ & Right superior temporal & 68 & $0.000 *$ & 57 & 1 & -12 \\
\hline \multirow[t]{2}{*}{$N C>A D$} & Right superior temporal & 371 & $0.000 * \star$ & 40 & -2 & -14 \\
\hline & Right ParaHippocampal & 163 & $0.000 * \star$ & 29 & -12 & -33 \\
\hline \multirow[t]{3}{*}{$S C D>A D$} & Right ParaHippocampal & 127 & $0.000 * \star$ & 24 & 2 & -30 \\
\hline & Right superior temporal & 254 & $0.000 * *$ & 42 & -7 & -15 \\
\hline & Left ParaHippocampal & 146 & $0.000 * \star$ & -26 & -5 & -28 \\
\hline $\mathrm{MCl}>\mathrm{AD}$ & Right superior temporal & 26 & $0.018 * \star$ & 41 & -11 & -13 \\
\hline \multicolumn{7}{|c|}{ * $\mathrm{P}<0.001$, uncorrected, voxel-wise level } \\
\hline \multicolumn{7}{|c|}{$\star \star \mathrm{P}<0.05$, FWE corrected, cluster-wise level } \\
\hline
\end{tabular}


Table 6

Reginal GM volume and cortical thickness related to AVLT-H, BVMT-R, SDMT

\begin{tabular}{|c|c|c|c|c|c|c|c|c|c|}
\hline \multicolumn{2}{|c|}{ Related to GMV/CT } & \multirow{3}{*}{$\begin{array}{l}\text { Areas } \\
\text { Left } \\
\text { hippocampus }\end{array}$} & \multirow{3}{*}{$\begin{array}{l}\text { K } \\
\text { voxel } \\
1342 \\
\end{array}$} & \multirow{2}{*}{\multicolumn{2}{|c|}{$P_{(\text {FWE-Corr) }}{ }^{*}$}} & \multirow{3}{*}{\begin{tabular}{|l} 
Z value \\
-27
\end{tabular}} & \multicolumn{3}{|c|}{ MNI coordinates } \\
\hline & & & & & & & \multirow{2}{*}{$\mathbf{x}$} & \multirow{2}{*}{$\begin{array}{r}y \\
-14\end{array}$} & \multirow{2}{*}{$\frac{\mathbf{z}}{-14}$} \\
\hline $\begin{array}{l}\text { AVLT- } \\
\text { SDR }\end{array}$ & GMV & & & 0.000 & 7.91 & & & & \\
\hline & & $\begin{array}{l}\text { left } \\
\text { parahippocampal }\end{array}$ & 639 & 0.000 & 5.40 & -21 & & -35 & -5 \\
\hline & & $\begin{array}{l}\text { Right } \\
\text { parahippocampal }\end{array}$ & 1230 & 0.000 & 6.83 & 30 & & -20 & -15 \\
\hline & & $\begin{array}{l}\text { Right } \\
\text { hippocampus }\end{array}$ & 1349 & 0.000 & 6.88 & 27 & & -12 & -14 \\
\hline & CT & $\begin{array}{l}\text { Right superior } \\
\text { temporal }\end{array}$ & 140 & 0.000 & 5.17 & 41 & & -0 & -20 \\
\hline & & $\begin{array}{l}\text { Right } \\
\text { ParaHippocampal }\end{array}$ & 196 & 0.000 & 4.78 & 19 & & -12 & -29 \\
\hline \multirow[t]{6}{*}{$\begin{array}{l}\text { AVLT- } \\
\text { LDR }\end{array}$} & GMV & $\begin{array}{l}\text { Left } \\
\text { hippocampus }\end{array}$ & 1203 & 0.000 & 6.96 & -27 & & -14 & -14 \\
\hline & & $\begin{array}{l}\text { left } \\
\text { parahippocampal }\end{array}$ & 1575 & 0.000 & 4.74 & -26 & & 3 & -26 \\
\hline & & $\begin{array}{l}\text { Right } \\
\text { parahippocampal }\end{array}$ & 1038 & 0.000 & 5.99 & 30 & & -20 & -15 \\
\hline & & $\begin{array}{l}\text { Right } \\
\text { hippocampus }\end{array}$ & 1217 & 0.000 & 6.50 & 21 & & -9 & -15 \\
\hline & CT & $\begin{array}{l}\text { Right superior } \\
\text { temporal }\end{array}$ & 116 & 0.001 & 4.96 & 42 & & 1 & -21 \\
\hline & & $\begin{array}{l}\text { Right } \\
\text { ParaHippocampal }\end{array}$ & 149 & 0.000 & 4.56 & 20 & & -14 & -29 \\
\hline \multirow[t]{8}{*}{$\begin{array}{l}\text { AVLT- } \\
\text { LCR }\end{array}$} & GMV & $\begin{array}{l}\text { Left } \\
\text { hippocampus }\end{array}$ & 1353 & 0.000 & 6.90 & -27 & & -14 & -14 \\
\hline & & $\begin{array}{l}\text { left } \\
\text { parahippocampal }\end{array}$ & 816 & 0.000 & 5.42 & -23 & & 5 & -29 \\
\hline & & Left fusiform & 433 & 0.000 & 5.52 & -32 & & 0 & -42 \\
\hline & & Right fusiform & 230 & 0.013 & 4.66 & 51 & & -30 & -9 \\
\hline & & $\begin{array}{l}\text { Right } \\
\text { parahippocampal }\end{array}$ & 1359 & 0.000 & 6.31 & 30 & & -18 & -17 \\
\hline & & $\begin{array}{l}\text { Right } \\
\text { hippocampus }\end{array}$ & 1252 & 0.000 & 6.78 & 18 & & -11 & -17 \\
\hline & CT & $\begin{array}{l}\text { Right superior } \\
\text { temporal }\end{array}$ & 63 & 0.004 & 4.70 & 42 & & 1 & -21 \\
\hline & & $\begin{array}{l}\text { left } \\
\text { ParaHippocampal }\end{array}$ & 133 & 0.000 & 4.27 & -23 & & 2 & -30 \\
\hline
\end{tabular}




\begin{tabular}{|c|c|c|c|c|c|c|c|c|c|}
\hline \multicolumn{2}{|c|}{ Related to GMV/CT } & \multirow{3}{*}{$\begin{array}{l}\text { Areas } \\
\text { Right } \\
\text { ParaHippocampal }\end{array}$} & \multirow{3}{*}{$\begin{array}{l}\text { K } \\
\text { voxel } \\
369 \\
\end{array}$} & \multicolumn{2}{|c|}{$\mathrm{P}_{\text {(FWE-Corr) }}{ }^{*}$} & \multirow[t]{2}{*}{$Z$ value } & \multicolumn{3}{|c|}{ MNI coordinates } \\
\hline & & & & & & & \multirow{2}{*}{$\mathbf{x}$} & \multirow{2}{*}{$\begin{array}{r}\mathbf{y} \\
-16\end{array}$} & \multirow{2}{*}{$\frac{\mathbf{z}}{-32}$} \\
\hline & & & & 0.000 & 5.34 & 32 & & & \\
\hline \multirow[t]{5}{*}{$\begin{array}{l}\text { AVLT- } \\
\text { REC }\end{array}$} & GMV & $\begin{array}{l}\text { Left } \\
\text { hippocampus }\end{array}$ & 1670 & 0.000 & 6.73 & -26 & & -11 & -12 \\
\hline & & $\begin{array}{l}\text { left } \\
\text { parahippocampal }\end{array}$ & 1858 & 0.000 & 6.73 & -20 & & -36 & -3 \\
\hline & & Left fusiform & 1496 & 0.000 & 6.42 & -23 & & -11 & -38 \\
\hline & & $\begin{array}{l}\text { Right } \\
\text { parahippocampal }\end{array}$ & 1978 & 0.000 & 6.73 & 21 & & -36 & -3 \\
\hline & & $\begin{array}{l}\text { Right } \\
\text { hippocampus }\end{array}$ & 1673 & 0.000 & 6.61 & 30 & & -20 & -15 \\
\hline \multirow[t]{2}{*}{$\mathrm{CT}$} & $\begin{array}{l}\text { left } \\
\text { ParaHippocampal }\end{array}$ & 383 & 0.000 & 5.21 & & -23 & 0 & -28 & \\
\hline & $\begin{array}{l}\text { Right } \\
\text { ParaHippocampal }\end{array}$ & 45 & 0.009 & 4.59 & & 26 & -5 & -29 & \\
\hline \multirow[t]{2}{*}{ AVLT-L } & GMV & $\begin{array}{l}\text { Left } \\
\text { hippocampus }\end{array}$ & 845 & 0.000 & 6.31 & -26 & & -15 & -11 \\
\hline & & $\begin{array}{l}\text { Right } \\
\text { hippocampus }\end{array}$ & 883 & 0.000 & 6.17 & 30 & & -18 & -17 \\
\hline \multirow[t]{2}{*}{$\begin{array}{l}\text { AVLT- } \\
\text { IR }\end{array}$} & GMV & $\begin{array}{l}\text { Left } \\
\text { hippocampus }\end{array}$ & 1172 & 0.000 & 7.08 & -27 & & -15 & -14 \\
\hline & & $\begin{array}{l}\text { Right } \\
\text { hippocampus }\end{array}$ & 1158 & 0.000 & 6.42 & 26 & & -14 & -12 \\
\hline \multirow[t]{2}{*}{ SDMT } & GMV & $\begin{array}{l}\text { Left } \\
\text { hippocampus }\end{array}$ & 54 & 0.000 & 5.61 & -30 & & -15 & -11 \\
\hline & & $\begin{array}{l}\text { Right } \\
\text { hippocampus }\end{array}$ & 181 & 0.001 & 5.22 & 20 & & -36 & 0 \\
\hline \multirow[t]{6}{*}{$\begin{array}{l}\text { BVMT- } \\
\text { IR }\end{array}$} & GMV & $\begin{array}{l}\text { Left } \\
\text { hippocampus }\end{array}$ & 1758 & 0.000 & 7.87 & -27 & & -12 & -15 \\
\hline & & $\begin{array}{l}\text { left } \\
\text { ParaHippocampal }\end{array}$ & 453 & 0.000 & 4.84 & -36 & & -21 & -29 \\
\hline & & $\begin{array}{l}\text { Right } \\
\text { hippocampus }\end{array}$ & 2840 & 0.000 & 7.02 & 30 & & -20 & -15 \\
\hline & & $\begin{array}{l}\text { Right } \\
\text { ParaHippocampal }\end{array}$ & 160 & 0.000 & 6.39 & 21 & & -9 & -17 \\
\hline & CT & $\begin{array}{l}\text { Right } \\
\text { ParaHippocampal }\end{array}$ & 176 & 0.000 & 4.91 & 22 & & -1 & -24 \\
\hline & & $\begin{array}{l}\text { Right superior } \\
\text { temporal }\end{array}$ & 46 & 0.009 & 4.39 & 56 & & -18 & -5 \\
\hline
\end{tabular}




\begin{tabular}{|c|c|c|c|c|c|c|c|c|c|}
\hline \multicolumn{2}{|c|}{ Related to GMV/CT } & \multirow[t]{2}{*}{ Areas } & \multirow{2}{*}{$\begin{array}{l}\text { K } \\
\text { voxel }\end{array}$} & \multicolumn{2}{|c|}{$P_{(\text {FWE-Corr })}{ }^{*}$} & \multirow[t]{2}{*}{$Z$ value } & \multicolumn{3}{|c|}{ MNI coordinates } \\
\hline & & & & & & & $\mathbf{x}$ & y & $\mathbf{z}$ \\
\hline \multirow[t]{7}{*}{$\begin{array}{l}\text { BVMT- } \\
\text { SDR }\end{array}$} & GMV & $\begin{array}{l}\text { Left } \\
\text { hippocampus }\end{array}$ & 1413 & 0.000 & 7.66 & -26 & & -12 & -14 \\
\hline & & $\begin{array}{l}\text { left } \\
\text { ParaHippocampal }\end{array}$ & 273 & 0.000 & 7.10 & -27 & & -29 & -9 \\
\hline & & $\begin{array}{l}\text { Right } \\
\text { hippocampus }\end{array}$ & 2625 & 0.000 & 7.82 & 30 & & -20 & -15 \\
\hline & & $\begin{array}{l}\text { Right } \\
\text { ParaHippocampal }\end{array}$ & 241 & 0.000 & 5.44 & 21 & & -6 & -41 \\
\hline & CT & $\begin{array}{l}\text { left } \\
\text { ParaHippocampal }\end{array}$ & 326 & 0.000 & 4.39 & -37 & & -4 & -27 \\
\hline & & $\begin{array}{l}\text { Right } \\
\text { ParaHippocampal }\end{array}$ & 465 & 0.000 & 5.31 & 25 & & 0 & -26 \\
\hline & & $\begin{array}{l}\text { Right superior } \\
\text { temporal }\end{array}$ & 130 & 0.000 & 4.96 & 54 & & -19 & -6 \\
\hline \multirow[t]{6}{*}{$\begin{array}{l}\text { BVMT- } \\
\text { LDR }\end{array}$} & GMV & $\begin{array}{l}\text { Left } \\
\text { hippocampus }\end{array}$ & 1016 & 0.000 & 8.44 & -26 & & -12 & -12 \\
\hline & & $\begin{array}{l}\text { Right } \\
\text { hippocampus }\end{array}$ & 2692 & 0.000 & 8.32 & 30 & & -20 & -15 \\
\hline & & $\begin{array}{l}\text { Right } \\
\text { ParaHippocampal }\end{array}$ & 540 & 0.000 & 5.80 & 21 & & -6 & -41 \\
\hline & & $\begin{array}{l}\text { left } \\
\text { ParaHippocampal }\end{array}$ & 422 & 0.000 & 7.00 & -21 & & -36 & -5 \\
\hline & CT & $\begin{array}{l}\text { Right } \\
\text { ParaHippocampal }\end{array}$ & 250 & 0.000 & 5.76 & 22 & & -2 & -24 \\
\hline & & $\begin{array}{l}\text { Right superior } \\
\text { temporal }\end{array}$ & 145 & 0.000 & 4.99 & 53 & & -19 & -7 \\
\hline \multirow[t]{5}{*}{$\begin{array}{l}\text { BVMT- } \\
\text { REC }\end{array}$} & GMV & $\begin{array}{l}\text { Left } \\
\text { hippocampus }\end{array}$ & 1323 & 0.000 & 8.62 & -24 & & -33 & -6 \\
\hline & & $\begin{array}{l}\text { Right } \\
\text { hippocampus }\end{array}$ & 2364 & 0.000 & 9.41 & 27 & & -29 & -9 \\
\hline & CT & $\begin{array}{l}\text { Right superior } \\
\text { temporal }\end{array}$ & 443 & 0.000 & 5.75 & 54 & & -18 & -5 \\
\hline & & $\begin{array}{l}\text { left } \\
\text { ParaHippocampal }\end{array}$ & 161 & 0.000 & 4.79 & -30 & & -11 & -27 \\
\hline & & $\begin{array}{l}\text { Right } \\
\text { ParaHippocampal }\end{array}$ & 184 & 0.000 & 4.31 & 27 & & -6 & -26 \\
\hline \multicolumn{10}{|c|}{${ }^{*} P_{F W E}<0.05$, voxel-wise level } \\
\hline
\end{tabular}

\section{Figures}




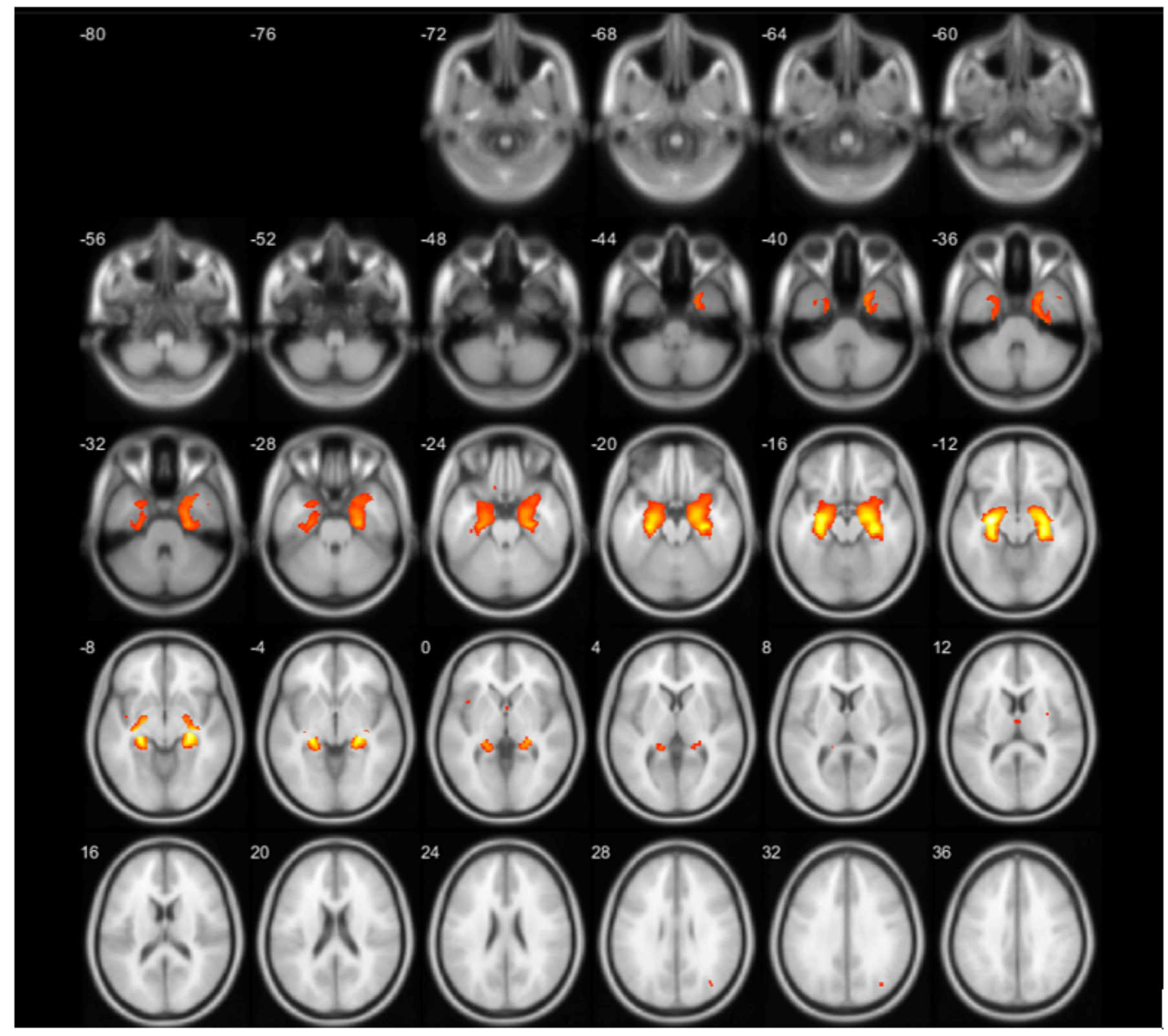

Figure 1

VBM analysis of group effects on regional brain grey matter, controlling for age, gender and TIV. $(\mathrm{P}<0.05, \mathrm{FWE}$ corrected, voxel-wise level). 

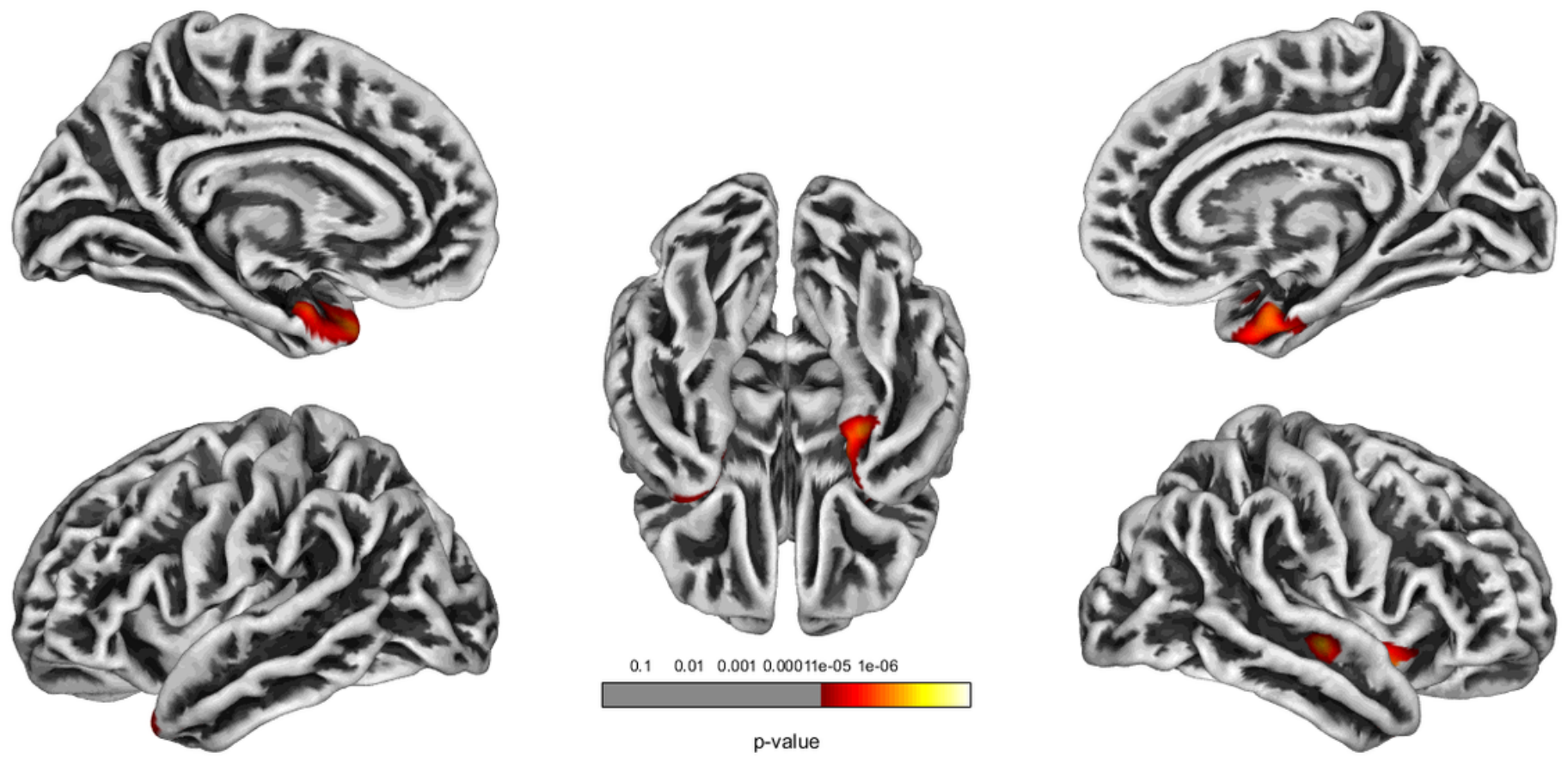

Figure 2

SBM analysis of group effects on regional cortical thickness, controlling for age and gender. $(\mathrm{P}<0.05$, FWE corrected, voxel-wise level). 

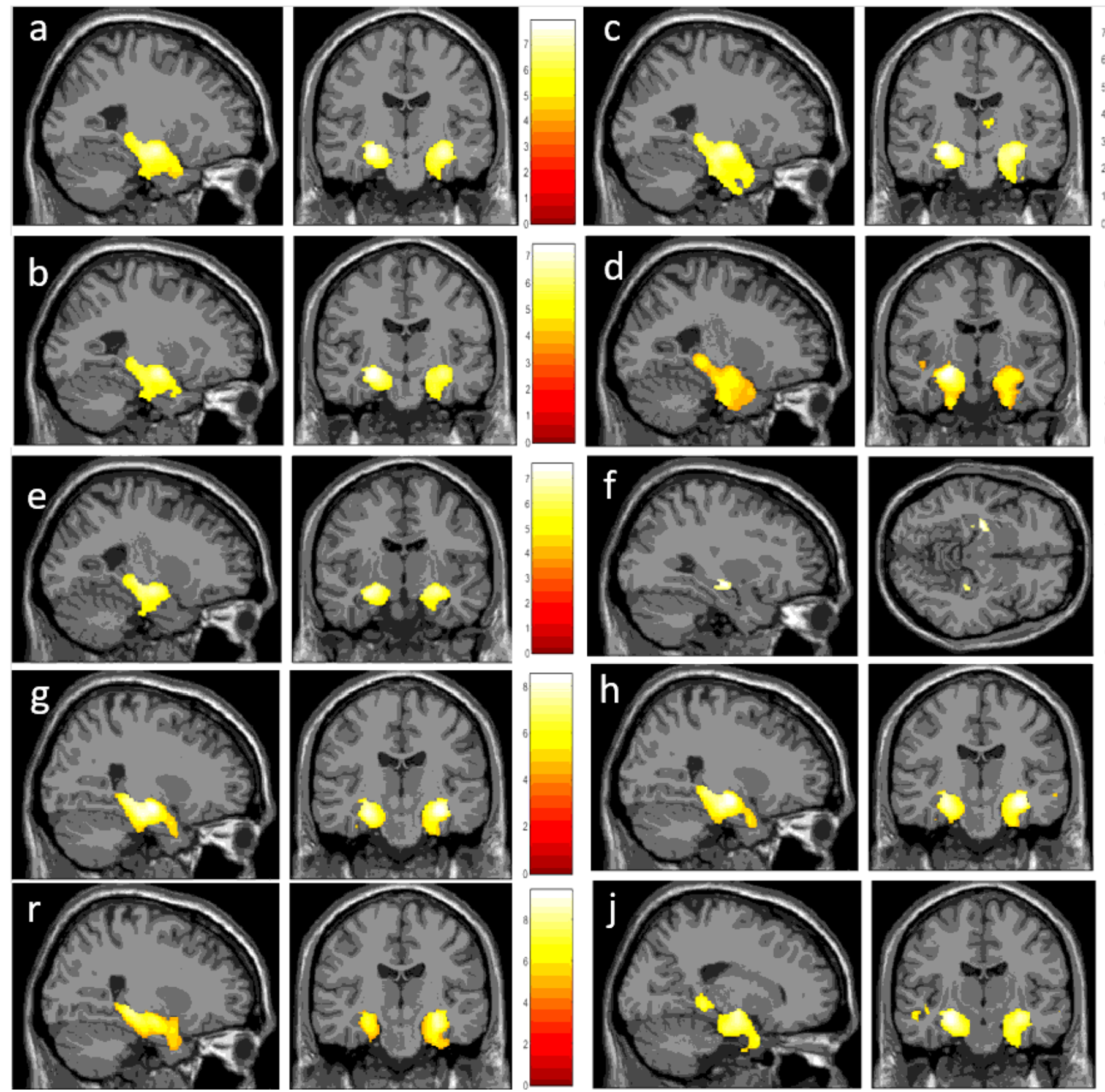

Figure 3

Multiple regression models were established, grey matter volumes positively associated with AVLT_H scores (a: AVLTSDR, b: AVLT-LDR, c: AVLT-LCR, d: AVLT-REC, e: AVLT-IR f: SDMT, g: BVMT-SDR, h: BVMT-LDR, r: BVMT-REC, j: BVMT-IR), controlling for age, gender and TIV. ( $P<0.05$, FWE corrected, voxel-wise level). 

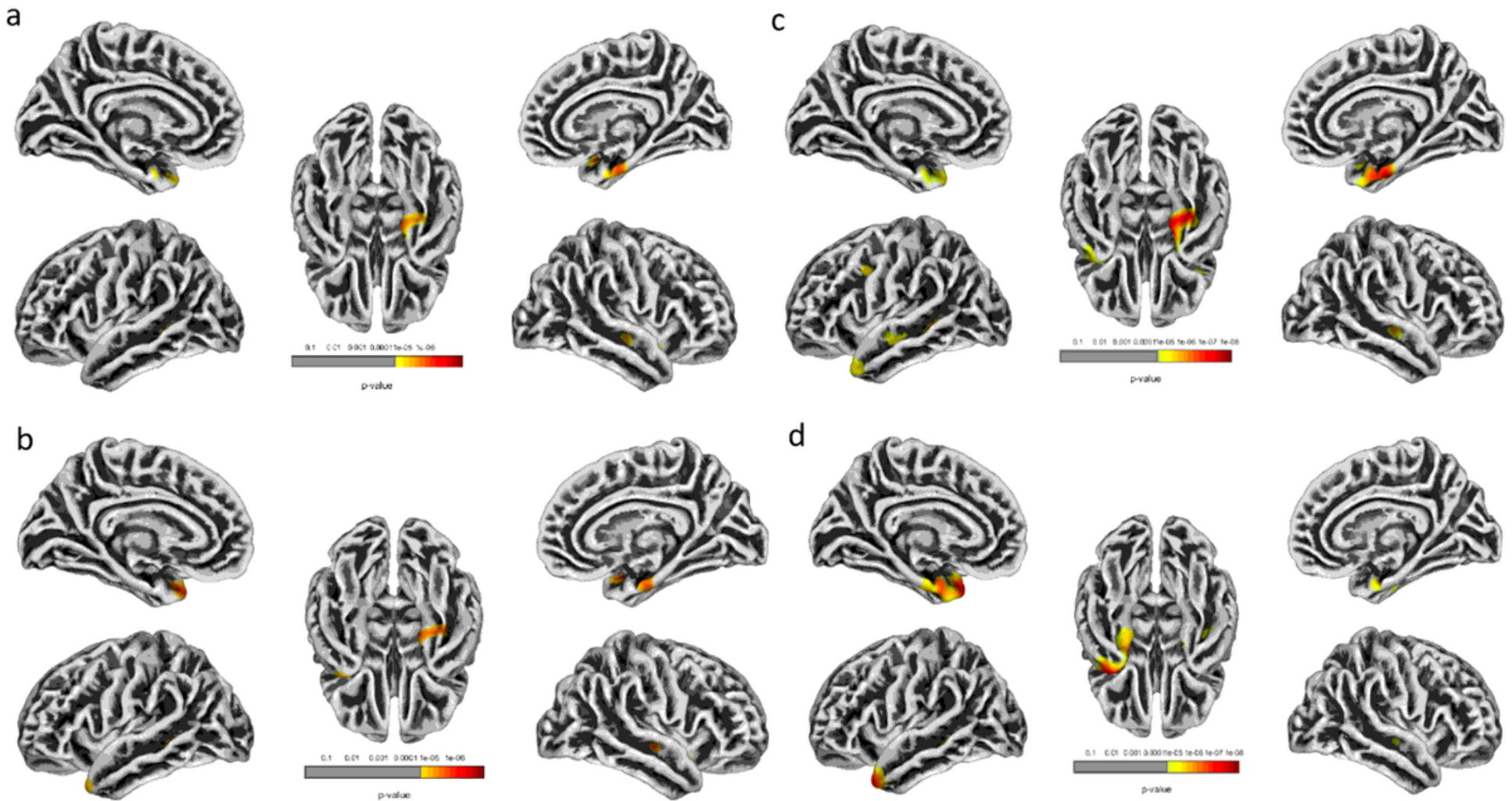

Figure 4

Multiple regression models were established, cortical thickness positively associated with AVLT_H scores (a: AVLT-SDR, b: AVLT-LDR, c: AVLT-LCR, d: AVLT-REC), controlling for age and gender. ( $P<0.05$, FWE corrected, voxel-wise level).

e
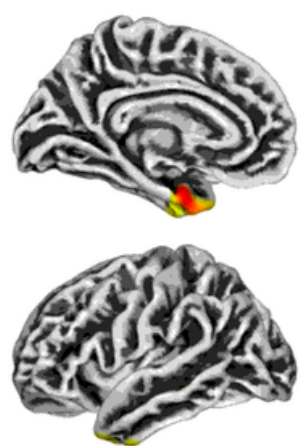

g
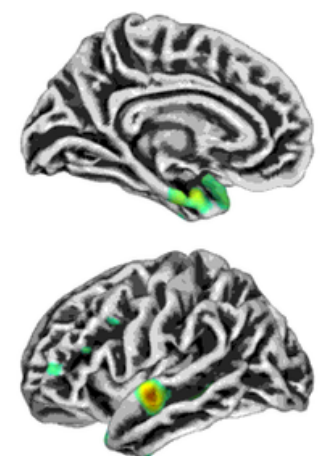
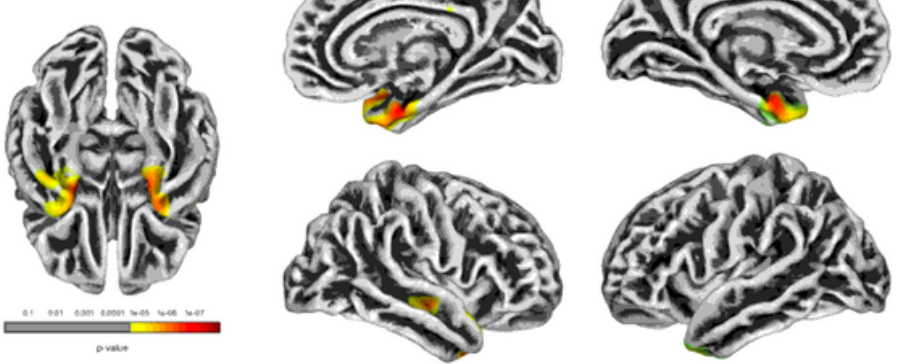

$\mathrm{h}$
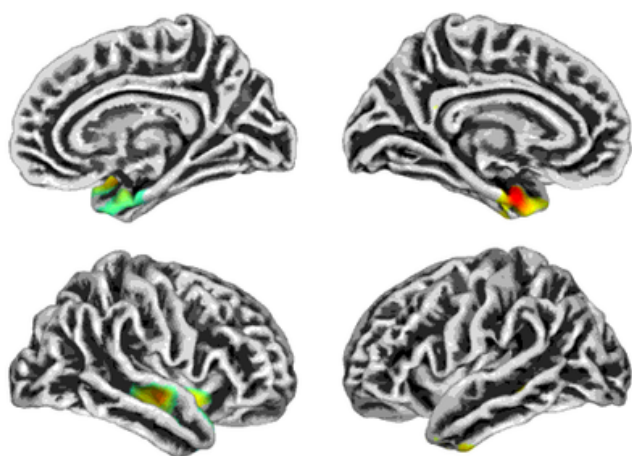
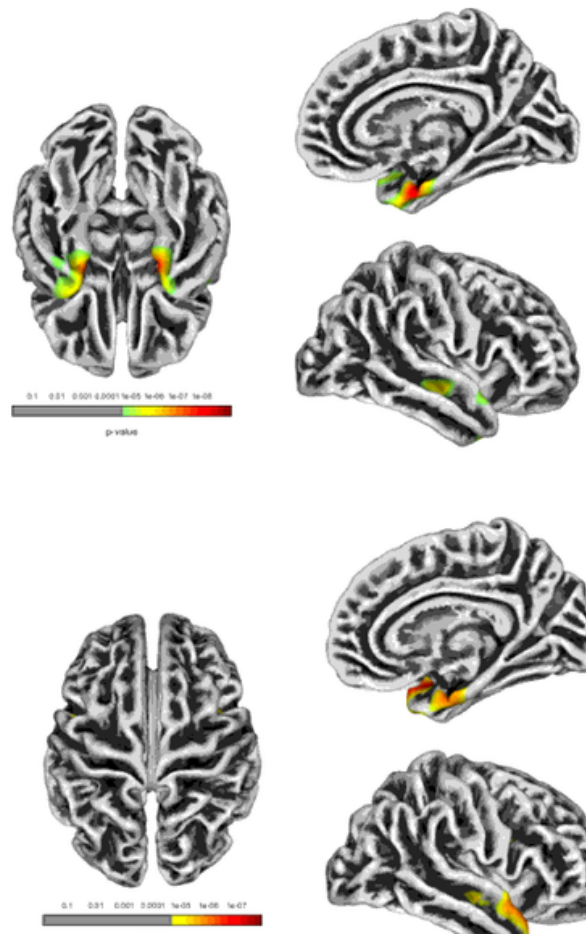

Figure 5 
Multiple regression models were established, cortical thickness positively associated with BVMT-R scores (e: BVMT-SDR, f: BVMT-LDR, g: BVMT-REC, h: BVMT-IR), controlling for age and gender. ( $P<0.05$, FWE corrected, voxel-wise level).
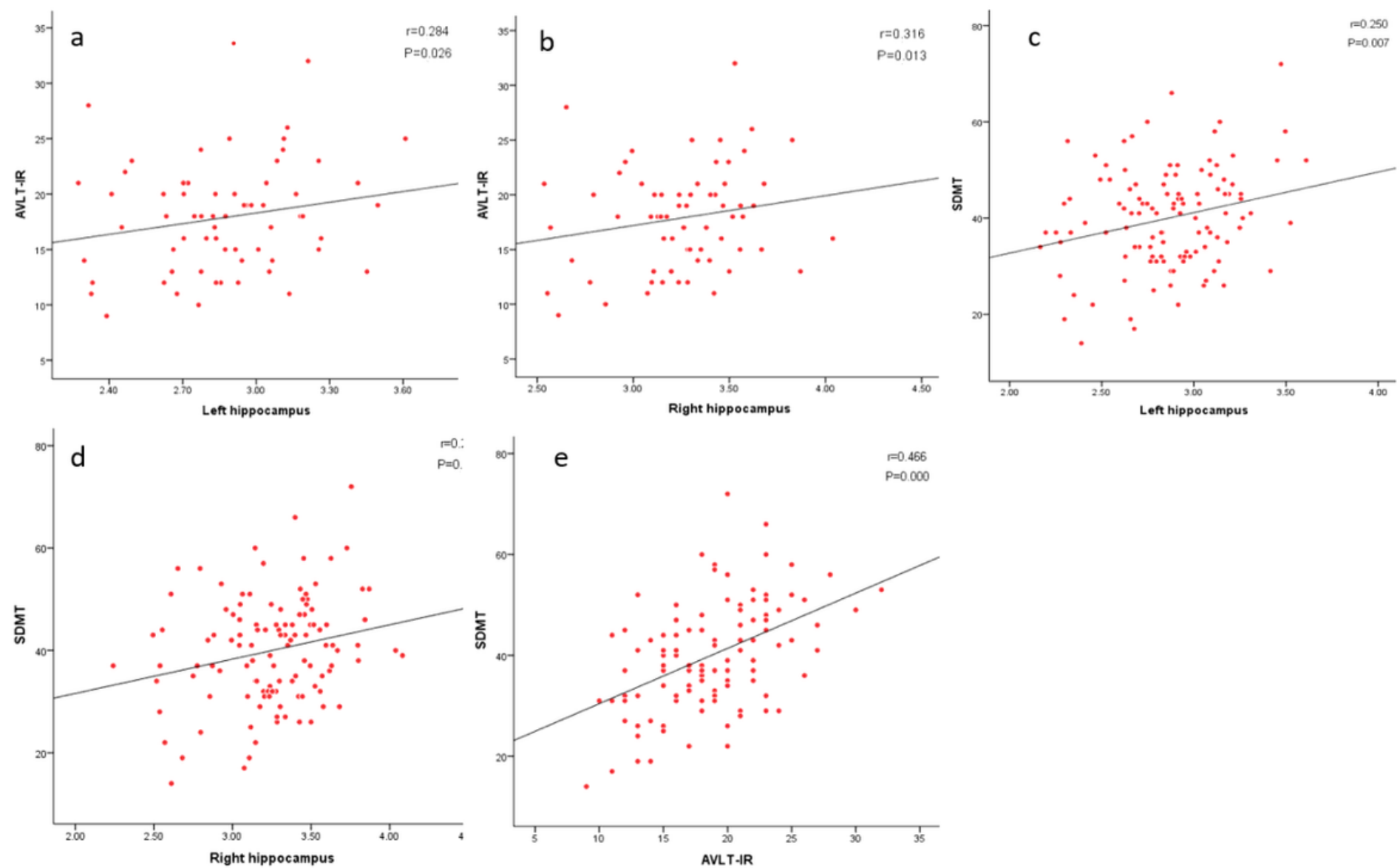

Figure 6

In SCD group, AVLT-IR was positively correlated with bilateral hippocampus (a, b). In NC and SCD group, SDMT was significantly positively correlated with bilateral hippocampus (c, d) and AVLT-IR (e). 